\title{
ORTHOPAEDIC SURGICAL TECHNIQUE GUIDES: ARE THEY READILY AVAILABLE IN AN ELECTRONIC FORMAT?
}

\author{
Dr Navid Nazarian MBBS ${ }^{1}$, Dr Christopher J Wall MBBS ${ }^{1}$, Dr Gayan Padmasekara MBBS ${ }^{1}$ \\ ${ }^{1}$ Department of Orthopaedics, Southern Health, Melbourne, Australia \\ Corresponding Author: nanazarian@yahoo.com
}

Background: New developments in mobile technology have had a profound effect on medical care worldwide. 1 In orthopaedic surgery a variety of implants and devices are used, and knowledge about their designs, specific features and surgical techniques is essential. The purpose of this study was to assess whether orthopaedic surgical technique guides are readily available in an electronic format

Methods: A list of thirty-two orthopaedic device companies currently trading in Australia was generated through a structured internet search and by reviewing a tertiary hospital database. The Apple store was searched for iPhone or iPad surgical technique applications for each company. Company websites were searched for downloadable surgical technique guides. Companies without downloadable surgical technique guides or iPhone applications were contacted via email or telephone to ask whether such products were in development.

Results: Of the thirty-two orthopaedic device companies studied, twenty-two (68.8\%) had surgical technique guides available for download on their websites. Four $(12.5 \%)$ companies had an iPhone or iPad application available in the Apple store.

Conclusion: Although many orthopaedic device companies have downloadable surgical technique guides on their websites, only a few had iPhone or iPad applications for their products. Further development of such products may be beneficial for orthopaedic surgeons.

Journal MTM 1:1:13-15, 2012 doi:10.7309/jmtm.5 www.journalmtm.com

\section{Introduction}

New developments in mobile technology have had a profound effect on medical care worldwide. ${ }^{1}$ Smartphones have been the latest revolution in telecommunication. ${ }^{2,3}$ The United Kingdom's National Statistics report growth in mobile phone ownership from $65 \%$ in 2001 to $81 \%$ in 2009 . $^{2}$ Due to their powerful computing capability, sizable memory, large screens and effective operating systems, the latest generation of smartphones are commonly viewed as handheld computers rather than telephones. ${ }^{2,3} \quad$ With thousands of medical applications available in Apple's

App Store, physicians use the Apple ${ }^{\circledR}$ iPhone and iPad as portable medical libraries. ${ }^{4}$ These new modalities of information access provide new opportunities for orthopaedic surgeons, allowing them to integrate technology into clinical practice. ${ }^{3,5} \mathrm{~A}$ database search revealed that iPhone and Android platforms have applications specifically created for orthopaedic surgery. ${ }^{5}$ In the United States, $84 \%$ of orthopaedic health professionals currently use a 
ris JMTM

smartphone, and $53 \%$ use applications in their clinical practice. $^{5}$ Ninety-six per cent of respondents stated they would like to see more applications available. ${ }^{5}$

In orthopaedic surgery a variety of implants and devices are used, and knowledge about their designs, specific features and surgical techniques is essential. This information is generally provided by orthopaedic device companies in booklet form and via their company representatives. The development and distribution of mobile applications, with their portability, updatability, speed and simplicity, make them an ideal tool for quick reference, especially in the operating theatre.

The purpose of this study was to assess whether orthopaedic surgical technique guides are readily available in an electronic format.

\section{Materials and Methods}

A list of thirty-two orthopaedic device companies currently trading in Australia was generated through a structured internet search and by reviewing a tertiary hospital database. The review was conducted by a single investigator. All company's websites were searched for downloadable surgical technique guides for their products. If a username and password was required to download such material, this was recorded. The Apple store was searched for iPhone or iPad surgical technique applications for each company. Companies without downloadable surgical technique guides or iPhone applications were contacted via email or telephone. They were asked whether they planned to release such information on their website or to develop an iPhone application.

\section{Results}

Of the thirty-two orthopaedic device companies studied, twenty-two (68.8\%) had surgical technique guides available for download on their websites. The other ten $(31.3 \%)$ companies had some product information available but surgical technique guides were not provided. Six of the twenty-two (27.3\%) companies with downloadable surgical technique guides required a username and password to access these documents.

Four (12.5\%) companies (Synthes ${ }^{\circledR}, \quad$ Stryker ${ }^{\circledR}$, Depuy ${ }^{\circledR}$, and Acumen $\left.{ }^{\circledR}\right)$ had an iPhone or iPad application available in the Apple store, while two $(6.3 \%)$ had declared they had applications in development. An example of an iPhone application is demonstrated in Figure 1.Twenty-six (81.3\%) companies did not have an iPhone application.

\section{ORIGINAL ARTICLE}

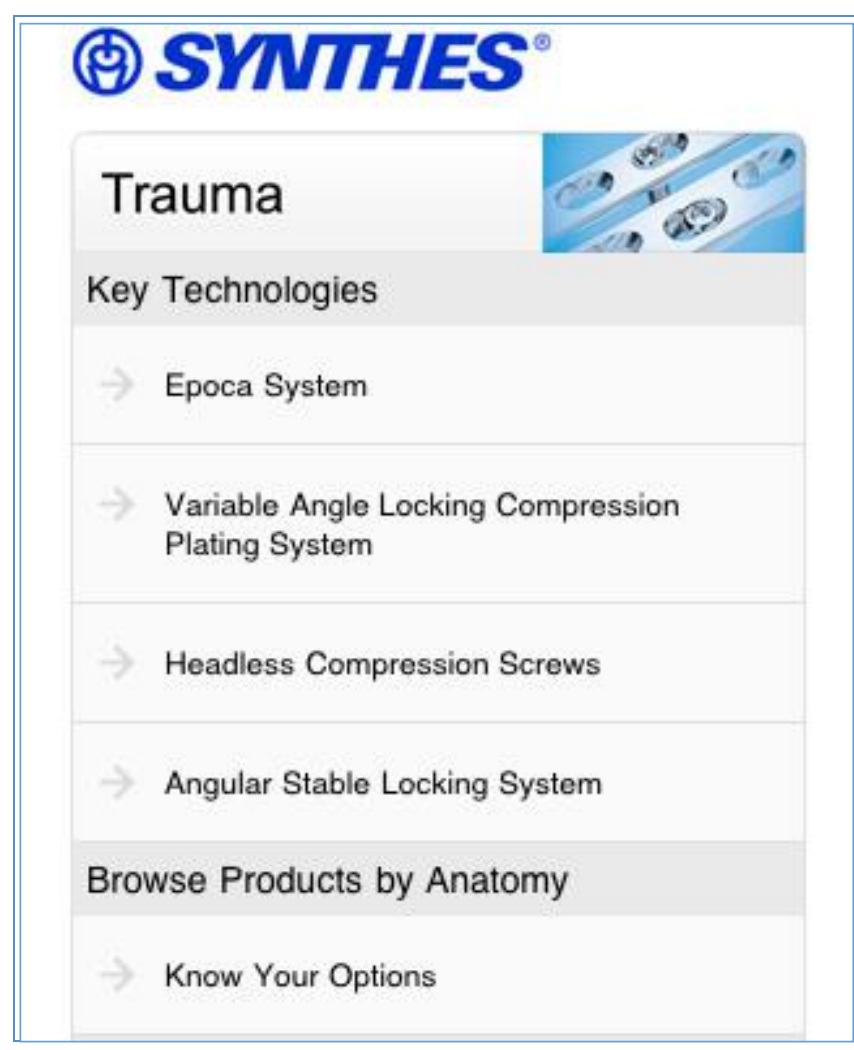

Figure 1. Synthes ${ }^{\circledR}$ iPhone application screenshot.

\section{Discussion}

The use of smartphones and applications is prevalent among orthopaedic residents, fellows and consultants, and most surgeons with smartphones use applications in their medical practice. ${ }^{2,5-7}$

Multiple iPhone and iPad applications are available for use in different medical disciplines including neurosurgery, paediatrics and anaesthetics, and for different audiences from medical students to consultants. ${ }^{8-11}$

New applications are released regularly, many free of charge. There are a number of applications that are designed for the iPhone that can be used on the iPad. ${ }^{12}$

Our study showed that only a few orthopaedic device companies provided an iPhone or iPad application for surgeons to use. There may be a number of reasons for this. Firstly, the need for these applications may not be appreciated by device companies, who may feel that currently available resources suffice. Secondly, the companies that currently have applications for iPhone or iPad are the largest providers of orthopaedic equipment and devices, so perhaps the number of products provided by smaller device companies does not warrant investment in applications for smartphones or tablets. Thirdly, device companies may be concerned that patients, and possibly other companies, have access to their product information. 


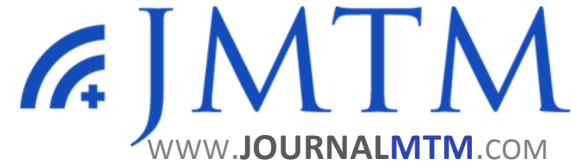

An additional consideration is that this study only reviewed the Apple "App" Store as these are the predominant devices in use at present. However, the Android $\AA$ application market is growing and needs to be evaluated in future studies.

A recent report revealed that the health-care market has been slow to integrate into the information superhighway because of concerns with regard to patient security, confidentiality, physician liability, and reliability of information. ${ }^{13}$ This may be one reason that orthopaedic device companies are reluctant to release product information in an electronic format.

Another important point is that currently available applications are sponsored by private companies which may not be required to adhere to any standard for medical content or accuracy. ${ }^{5,14}$ If this trend toward the use of privately funded educational material continues, regulations may need to be established to ensure that the information provided is accurate, honest, supported by peer-reviewed literature, and is free from conflict of interest. ${ }^{8}$

\section{Conclusion}

The majority of orthopaedic companies provided surgical technique guidelines in an electronic format. Only a minority of companies provided iPhone/ iPad applications with this information.

Further development of such products may be of benefit to orthopaedic surgeons.

\section{References}

1. Archbold HA, Guha AR, Shyamsundar S, McBride SJ, Charlwood P, Wray R. The use of multi-media messaging in the referral of musculoskeletal limb injuries to a tertiary trauma unit using: a 1-month evaluation. Injury 2005;36(4):560-6.

2. Boulos MN, Wheeler S, Tavares C, Jones R. How smartphones are changing the face of mobile and participatory healthcare: an overview, with example from eCAALYX. Biomed Eng Online 2011;10:24.

3. Burdette SD, Herchline TE, Oehler R. Surfing the web: practicing medicine in a technological age: using smartphones in clinical practice. Clin Infect Dis 2008;47(1):117-22.

\section{ORIGINAL ARTICLE}

4. Berger E. The iPad: gadget or medical godsend? Ann Emerg Med 2010;56(1):A21-2.

5. Franko OI. Smartphone apps for orthopaedic surgeons. Clin Orthop Relat Res 2011;469(7):2042-8.

6. Payne D, Godlee F. The BMJ is on the iPad. BMJ 2011;342:d283.

7. Savel RH, Munro CL. Scalpel, stethoscope, iPad: the future is now in the intensive care unit. Am J Crit Care 2011;20(4):275-7.

8. Franko OI, Bhola S. iPad apps for orthopedic surgeons. Orthopedics 2011;34(12):978-81.

9. Kiser K. The iPad project. Minn Med 2011;94(4):12-4.

10. Kubben PL. Neurosurgical apps for iPhone, iPod Touch, iPad and Android. Surg Neurol Int 2010;1:89.

11. Lacquiere DA, Courtman S. Use of the iPad in paediatric anaesthesia. Anaesthesia 2011;66(7):629-30.

12. Mashman W. The iPad in cardiology: tool or toy? JACC Cardiovasc Interv 2011;4(2):258-9.

13. Rozental TD, Lonner JH, Parekh SG. The Internet as a communication tool for academic orthopaedic surgery departments in the United States. J Bone Joint Surg Am 2001;83-A(7):987-91.

14. Beredjiklian PK, Bozentka DJ, Steinberg DR, Bernstein J. Evaluating the source and content of orthopaedic information on the Internet. The case of carpal tunnel syndrome. J Bone Joint Surg Am 2000;82-A(11):1540-3.

\section{Disclaimer}

All product names, logos, brands and other trademarks featured or referred to within the Journal of Mobile Technology in Medicine e-publication remain the property of their respective trademark holders.

These trademark holders are not affiliated with the Journal of Mobile Technology in Medicine, and do not sponsor or endorse this journal. 